\title{
EPIDEMIOLOGY
}

\section{Female Sexual Dysfunction Among Greek Women With Multiple Sclerosis: Correlations With Organic and Psychological Factors}

\author{
Charalampos Konstantinidis, MD, FEBU, FECSM, Moira Tzitzika, MSc, ECPS, BTEC, EFT, \\ Athanasios Bantis, MD, PhD, MSc, Archontia Nikolia, MSc, ${ }^{7}$ Michalis Samarinas, MD, FEBU, ${ }^{2}$ \\ Zisis Kratiras, MD, FEBU, ${ }^{2}$ Charalampos Thomas, MD, PhD, MSc, FECSM, and \\ Konstantinos Skriapas, MD, PhD, FEBU ${ }^{2}$
}

\begin{abstract}
Introduction: Multiple Sclerosis (MS) is a degenerative neurological disease that usually occurs between the ages of 20 and 50 years. Sexuality issues are important factors that affect the quality of life of patients.

Aim: To determine and evaluate the prevalence of female sexual dysfunction (FSD) in Greek women with MS and correlate it with organic and psychological factors.

Methods: 248 consecutive women with MS, aged over 18 who admitted to our outpatient clinics from February 2016 to March 2017 were included in the study. Demographics (age, marital status, menopause status, number of children) and disease-related data such as the duration of the disease, Expanded Disability Status Scale (EDSS) and medication for MS obtained.

Main Outcome Measure: All participants completed the Greek validated versions of the Depression, Anxiety, Stress Scale (DASS-21) and the Female Sexual Function Inventory (FSFI) questionnaires. Statistics used to estimate the prevalence of FSD and its correlation with organic (age, EDSS, duration of the disease, menopause status) and psychological factors (depression, anxiety, stress).

Results: FSD was diagnosed in $64.5 \%$ of our sample. Age was associated with most subscales of the FSFI. There was no significant correlation in FSFI subscales with the disease duration. Correlation of EDSS and FSFI scores was found to be statistically significant with a negative correlation in all subscales apart from the Satisfaction subscale. Regarding the association between DASS domains and FSFI subscales, there were no significant correlations.

Conclusion: FSD is common among Greek women; it is influenced by age, severity of disease, and it is independent of the existence of depression, anxiety, and stress. Konstantinidis C, Tzitzika M, Bantis A, et al. Female sexual dysfunction among Greek women with multiple sclerosis: Correlations with organic and psychological factors. Sex Med 2019;7:19-25.
\end{abstract}

Copyright (c) 2018, The Authors. Published by Elsevier Inc. on behalf of the International Society for Sexual Medicine. This is an open access article under the CC BY-NC-ND license (http://creativecommons.org/licenses/by-nc-nd/4.0/).

Key Words: Multiple Sclerosis; Female Sexual Dysfunction; FSFI; DASS

Received June 17, 2018. Accepted November 14, 2018.

'Urology \& Neuro-urology Unit, National Rehabilitation Center, llion, Athens, Greece;

¿Urology Department, General Hospital of Larisa “Koutlibanio", Larisa, Greece

Copyright (c) 2018, The Authors. Published by Elsevier Inc. on behalf of the International Society for Sexual Medicine. This is an open access article under the CC BY-NC-ND license (http://creativecommons.org/ licenses/by-nc-nd/4.0/J.

https://doi.org/10.1016/j.esxm.2018.11.003

\section{INTRODUCTION}

Multiple sclerosis (MS) is a degenerative, neurologic disease affecting 2.5 million people worldwide. Onset is usually between the ages of 20 and 50 with most cases diagnosed between the ages of 20 and $30 .^{1,2}$ More than twice as many young women are diagnosed with MS than men. ${ }^{2}$ Typically, the first symptoms of MS occur between the ages of 20 and 40 years, therefore issues concerning sexual function are important factors affecting patients' quality of life (QoL) and fertility. ${ }^{3}$ When the patient is confronted with MS, sexuality is reshaped against a foundation of previous sexual experiences and expectations. ${ }^{2}$ 
Female sexuality is a multidimensional subject. ${ }^{4}$ The female sexual function is a complex process involving physiological, psychosocial, and interpersonal factors. ${ }^{3}$ It is estimated that $40-80 \%$ of female MS patients suffer from female sexual dysfunction (FSD). ${ }^{3-7}$ Young women affected by MS are challenged with finding a partner, building a relationship, creating families, and leading routine sexual activities. ${ }^{3}$ Constructions of sexuality such as physical sexual responses, perceptions of appearance and attractiveness to self and others, communication and relationships, self-image and self-esteem, and the sense of affirmation and acknowledgment that the woman experienced from others in her everyday life will influence sexual behavior and relationships after diagnosis. ${ }^{8}$

There has been less attention paid to the frequency and characteristics of sexual complaints among women with MS in comparison with men. ${ }^{9,10}$ However, some studies showed that women with MS experience sexual dysfunction more commonly and with a higher level than men. ${ }^{10-12}$ Previous studies found variable relationships between FSD and age, disease duration, disability, disease course, and other symptoms of the disease. ${ }^{11-15}$ Zivadinov et $\mathrm{al}^{13}$ indicated that sexual dysfunction in women was significantly correlated with disability, age, the primary progressive pattern of the disease and symptoms, such as depression, bladder dysfunction, fatigue, and cognitive problems. No relationship was found between disease duration, secondary progressive MS, and bowel dysfunction.

Studies that have been conducted in women with other neurodegenerative diseases have shown that many factors other than the disease contribute to FSD. Varanda et $\mathrm{al}^{16}$ indicated that in women with Parkinson's disease, sexual dysfunction is more prevalent and is predicted by older age and severity of depressive symptoms. Similar results have been found in women with other degenerative diseases such as rheumatoid arthritis (RA). Yilmaz et $\mathrm{al}^{17}$ found that RA had negative results in the sexual function of women with the disease. Presence of depressive symptoms with RA and increased disease severity increase the degree of sexual dysfunction.

Depression in literature is found to have a very high rate associated with MS. ${ }^{18-22}$ Significant correlations with depression and sexual dysfunction have also been found in other chronic illness (eg, among diabetes patients), supporting a causative role of psychological factors for sexual problems. ${ }^{23-25}$ Apart from antidepressive treatment, depression itself may cause a progressive decline in interest in sexual behavior leading to low libido, difficulty in sexual arousal, orgasm problems, and frank sexual aversion, ${ }^{26}$ whereas anxiety was found to have the most important influence on the reduced frequency of intercourse. ${ }^{27}$

Menopause (either natural or surgical) is a factor that has been associated with sexual dysfunction in a number of studies. For some women, menopause and midlife are a time of major change, including changes in employment, family structure, and sexual function. ${ }^{28-30}$ In MS, menopause has been associated with all of these life changes and symptoms and possibly worsened MS symptoms as well. ${ }^{31}$ For this reason, we decided to collect data from our sample regarding this issue and to find any association with the other variables.

Although many studies have been conducted about the issue of sexual dysfunction in patients with MS in different countries, ${ }^{2-15}$ there is a lack of data concerning the Greek population. There is only 1 study made in the Greek population with MS about sexuality, but it involved only newly diagnosed women. ${ }^{32}$ So we decided to investigate the prevalence of sexual dysfunction among Greek women with MS and to make correlations with other variables such as the severity of the disease, depression, anxiety, stress, and demographics.

The aim of this study was first to determine and evaluate the prevalence of FSD in Greek women with MS and second to correlate it with organic and psychological factors such as the severity of the disease, the disease duration along with the presence of depression, anxiety, and stress in women. Our main dependable variable was sexual dysfunction as it is demonstrated and evaluated by the FSFI. Independable variables were depression, anxiety, stress, age, menopause, and the severity of the disease as it is reflected by the Expanded Disability Status Scale (EDSS) score. We chose these because past studies have indicated that FSD mainly depends on these risk factors either in patients or in healthy women..$^{2-15,32,42}$ Our investigation hypotheses are:

H1: Sexual dysfunction will have high rates among women with MS

H2: Sexual dysfunction will be higher in women with depression, anxiety, or stress according to past studies

H3: Sexual dysfunction will be higher in older women

H4: Sexual dysfunction will be higher in women with menopause

H5: Sexual dysfunction will be more prevalent in women with more severe MS (higher EDSS score)

\section{MATERIALS AND METHOD}

In this study, we contacted 267 consecutive women with MS, all patients of outpatient urology and neuro-urology clinics of the affiliating departments that took part in the study, during the period from February 2016 to March 2017. From the 267 women, 248 answered the questionnaires as asked. The study was approved by our institution's Ethical Committee.

Inclusion criteria were definite MS and age over 18 . Written informed consent was obtained from each participant before answering the questionnaires, giving us the permission to use their data for statistical purposes and have their questions about the study answered. Demographic data included age, marital status, menopause status, and number of children. For statistical purposes, we divided women's ages into 3 categories: $18-34$, 
35-50, and 50+. Additionally, disease-related data such as the duration of the disease, EDSS score, and medication for MS was obtained. All participants completed the Greek validated version of the Depression, Anxiety, Stress Scale 21 (DASS-21) ${ }^{33-35}$ questionnaire along with the Greek validated version of the Female Sexual Function Inventory (FSFI). ${ }^{38}$

The DASS-21 questionnaire is the short version of the DASS index that consisted initially of 42 questions and has 3 subscales: The Depression scale has subscales assessing dysphoria, hopelessness, devaluation of life, self-deprecation, lack of interest/involvement, anhedonia, and inertia. The Anxiety scale assesses autonomic stimulation, skeletal muscle effects, situational anxiety, and subjective experience of anxious affect. The Stress scale's subscales highlight levels of non-chronic arousal through difficulty relaxing, nervous stimulation, and being easily upset/agitated, irritable/over-reactive, and impatient. The DASS-21 is based on a dimensional rather than a categorical conception of psychological disorder. The assumption on which the DASS-21 development was based (and which was confirmed by the research data) is that the differences between depression, anxiety, and stress experienced by normal subjects and clinical populations are essentially differences of degree. The DASS-21, therefore, has no direct implications for the allocation of patients to discrete diagnostic categories postulated in classificatory systems such as the Diagnostic and Statistical Manual of Mental Disorders and International Classification of Diseases. The total score ranges from $0-28+$ for the Depression Subscale, $0-20+$ for the Anxiety subscale, and $0-34+$ for the Stress Subscale. ${ }^{20-22}$ The score for every subscale is demonstrated in Appendix 1.

The FSFI is a brief instrument for assessment of female sexual function that consists of 19 questions and classifies sexual dysfunction in the domains of (a) desire, (b) arousal, (c) lubrication, (d) orgasm, (e) satisfaction, and (f) pain. Higher scores indicate better sexual functioning and the total score range is $2-36 .^{36-38}$ FSD was defined as a total score of 26 or less as indicated in the Greek Validated version. ${ }^{38}$ In addition, the score of each domain was calculated.

Neurologic impairment and disability were measured by the EDSS. ${ }^{39}$ The EDSS quantifies disability in 8 Functional Systems and allows neurologists to assign a Functional System Score in each of these domains:

- pyramidal - weakness or difficulty moving limbs

- cerebellar - ataxia, loss of coordination, or tremor

- brainstem - problems with speech, swallowing, and nystagmus

- sensory - numbness or loss of sensations

- bowel and bladder function

- visual function

- cerebral (or mental) functions

- other

EDSS steps 1.0-4.5 refer to people with MS who are fully ambulatory. EDSS steps 5.0-9.5 are defined by the impairment
Table 1. Demographic data

\begin{tabular}{|c|c|c|c|c|}
\hline & $\mathrm{N}$ & $\%$ & Mean & St. Dev. \\
\hline Age, Total & 248 & 100 & 45.84 & 8.448 \\
\hline $18-34$ & 28 & 11,3 & & \\
\hline $35-50$ & 146 & 58,9 & & \\
\hline $50+$ & 74 & 29,8 & & \\
\hline \multicolumn{5}{|l|}{ Menopause } \\
\hline Yes & 96 & 38.7 & & \\
\hline No & 152 & 61.3 & & \\
\hline \multicolumn{5}{|l|}{ Marital Status } \\
\hline Single & 48 & 19.4 & & \\
\hline In a Relationship & 22 & 8.9 & & \\
\hline Married & 116 & 46.8 & & \\
\hline Divorced & 48 & 19.4 & & \\
\hline Widow & 14 & 5.6 & & \\
\hline \multicolumn{5}{|l|}{ No. of Children } \\
\hline 0 & 92 & 37.1 & & \\
\hline 1 & 70 & 28.2 & & \\
\hline 2 & 62 & 25.0 & & \\
\hline 3 & 24 & 9.7 & & \\
\hline Duration of the disease & & & 12.78 & 2.1855 \\
\hline $0-10$ years & 126 & 50.8 & & \\
\hline 11-20 years & 84 & 33.9 & & \\
\hline $21+$ years & 38 & 15.3 & & \\
\hline \multicolumn{5}{|l|}{ EDSS Score } \\
\hline $0-2.5$ & 96 & 38.7 & & \\
\hline $3.0-5.0$ & 128 & 51.6 & & \\
\hline $5.5+$ & 24 & 9.7 & & \\
\hline
\end{tabular}

to ambulation. The detailed EDSS score is described in Appendix 2.

Statistical analysis used to calculate the prevalence of FSD and its correlation with organic (age, EDSS, duration of the disease, menopause status) and psychological factors (depression, anxiety, stress). For this purpose, we used the Statistical Package for the Social Sciences (SPSS) version 18 (SPSS Inc, Chicago, IL, USA). Frequencies were calculated for each variable. In the comparisons between groups, independent $t$-test, Pearson correlation was also used to clarify relationships between quantifiable variables. A $P$ value $<.05$ was considered statistically significant.

\section{RESULTS}

248 of 267 women completed the questionnaires as asked. 19 women refused to participate in the study. Mean age of our sample was 45.84 years with a standard deviation of 8.448 . The majority of women were in the second age category $(35-50$ years, $\mathrm{N}=46$, $58.9 \%)$ and were not in menopause $(\mathrm{N}=156,52.9 \%)$. Most of them were married $(\mathrm{N}=116,46.8 \%)$, had children $(\mathrm{N}=156$, $62.9 \%)$, with a mean duration of the disease 12.78 years $( \pm$ $2.1855)$ and for the majority, EDSS score was 3.5-5.0 $(\mathrm{N}=128$, $51.6 \%$ ). The main characteristics of the study population (demographic data) are demonstrated in Table 1. 
Table 2. Depression, Anxiety, Stress Scale (DASS-21) subscale scores

\begin{tabular}{|c|c|c|c|c|c|c|}
\hline & \multicolumn{2}{|c|}{ Depression } & \multicolumn{2}{|c|}{ Anxiety } & \multicolumn{2}{|c|}{ Stress } \\
\hline & $\mathrm{N}$ & $\%$ & $\mathrm{~N}$ & $\%$ & $\mathrm{~N}$ & $\%$ \\
\hline Normal & 106 & 42.7 & 104 & 41.9 & 124 & 50.0 \\
\hline Mild & 20 & 8.1 & 14 & 5.6 & 34 & 13.7 \\
\hline Moderate & 66 & 26.6 & 58 & 23.4 & 26 & 10.5 \\
\hline Severe & 30 & 12.1 & 12 & 4.8 & 38 & 15.3 \\
\hline Extremely severe & 26 & 10.5 & 60 & 24.2 & 26 & 10.5 \\
\hline Total & 248 & 100 & 248 & 100.0 & 248 & 100.0 \\
\hline
\end{tabular}

According to the FSFI score $(\leq 26)$, FSD was diagnosed in $160(64.5 \%)$ of women who participated in this study. For these patients, the presence of FSD was found not to be associated with MS drugs. Women with FSD were older (mean age 47.29 \pm 7.628 vs $43.05 \pm 8.783$ ), half of them were in menopause $(\mathrm{N}=72,45 \%$ in menopause with $\mathrm{FSD}$ vs $\mathrm{N}=88,55 \%$ women with FSD not in menopause but with no significant correlation between menopause and FSFI subscales), had longer disease duration (mean duration of MS $13.66 \pm 8.331$ vs $11.62 \pm 6.047)$, and had higher EDSS scores than women without FSD (mean $3.69 \pm 1.3537$ vs $3.03 \pm 1.4986$ ).

According to DASS, $42.7 \%(\mathrm{~N}=106)$ of women scored Normal in Depression scale vs $57.3 \%(\mathrm{~N}=142)$ who scored from Mild to Extremely Severe, $41.9 \%(\mathrm{~N}=104)$ scored Normal in Anxiety Subscale vs $58.1 \%(\mathrm{~N}=144)$ who had mild to extremely severe anxiety and 50\% (N =124) scored normally in Stress Scale vs the other $50 \%$ who had mild to severe stress. All the data regarding the DASS-21 subscales are demonstrated in Table 2.

We conducted a correlation analysis between clinical variables and DASS scores to see how depression, anxiety, and stress are correlated with age, menopause, duration of the disease, and EDSS (Table 3). Age was associated with all DASS subscales. EDSS had a significant correlation with Depression and Stress subscales but not with anxiety, which means that the severity of MS is associated with higher rates of depression and stress among women patients. Surprisingly, there was no significant correlation between depression, anxiety, stress, and MS duration. Concerning menopause, we conducted Pearson Chi-Square analysis and found that from the 96 women of the sample who were in menopause, $41.7 \%$ of them had normal depression score vs $58.3 \%$ who had from mild to extremely severe depression. Regarding Anxiety and Stress subscales, $45.8 \%$ of women in menopause had a normal score vs $54.2 \%$ who scored from mild to extremely severe.

The correlation analysis between clinical variables and FSFI subscales scores showed that age had a significant positive correlation with Desire, and negative correlation with Lubrication, Orgasm, and Pain subscales of the FSFI. Additionally, there was no significant correlation in any FSFI subscale with duration of the disease. Correlation of EDSS and FSFI scores were found to
Table 3. Correlations of clinical variables (age, Expanded Disability Status Scale [EDSS]] with Depression, Anxiety, Stress Scale (DASS-21) scores

\begin{tabular}{|c|c|c|c|c|c|c|}
\hline & \multicolumn{2}{|c|}{ Depression } & \multicolumn{2}{|l|}{ Anxiety } & \multicolumn{2}{|c|}{ Stress } \\
\hline & $r$ & $P$ & $r$ & $P$ & $r$ & $p$ \\
\hline AGE & $.137^{*}$ & .039 & $.223^{\dagger}$ & .000 & $.230^{\dagger}$ & .000 \\
\hline EDSS & $.711^{\dagger}$ & .000 & -.027 & .817 & $.172^{*}$ & .007 \\
\hline MS Years & .068 & .286 & .020 & .757 & .021 & .745 \\
\hline
\end{tabular}

*Correlation is significant at the 0.05 level (2-tailed).

${ }^{\dagger}$ Correlation is significant at the 0.01 level (2-tailed).

be statistically significant with a positive correlation in Desire Subscale and negative in Lubrication, Orgasm, and Pain.

Finally, we conducted a correlation analysis between FSFI scores and DASS scores to investigate the way that sexual problems correlate with depression, anxiety, and stress in our patients. Although there was a negative correlation between depression, anxiety, and stress with all FSFI subscales, there was no significant correlation between all DASS subscales and FSFI. Table 4 shows all correlations between clinical variables and FSFI scores.

\section{DISCUSSION}

Our study was designed to evaluate FSD in women with MS in our outpatient clinics. From the results, it appears that FSD is a common problem among Greek female MS patients. These results confirm our first hypothesis which was that sexual dysfunction would be at high rates in women with MS. Our results are similar to the outcomes of previous studies $^{2-15,32,40-46}$ done in MS populations of various nationalities regarding FSD. Reported changes in sexual function in women with MS include diminished sexual desire, vaginal lubrication, and orgasmic capacity. ${ }^{40-46}$ In a case-control study, Zorzon showed that sexual function of women with MS is significantly reduced compared with healthy female controls. ${ }^{43}$ Neurologic impairments that could potentially affect sexual function in women with MS include abnormal genital sensation, pain, pelvic floor muscle weakness, fatigue, and muscle spasms. ${ }^{43-46}$

Women with MS may have a negative self-image and less confidence about their sexuality. This could lead to the development of anxiety and depression and the potential for sexual dysfunction. ${ }^{47}$ Because there was an indication from the literature that depression would affect sexual functioning among women with MS, we queried our sample about depression and included it as a variable in the analysis. Regarding our second hypothesis of higher rates of sexual dysfunction in women with depression, anxiety, or stress, we surprisingly found that there were no significant correlations between FSD and symptoms of depression, anxiety, and stress. This finding is in contrast with previous studies on this topic ${ }^{2-15,18-22,47}$ and needs to be explained perhaps in a new study with a larger sample or with more data about the psychological state of people with MS. 
Table 4. Correlations of clinical variables (age, EDSS, MS duration, depression, anxiety, stress) with Female Sexual Function Inventory

\begin{tabular}{|c|c|c|c|c|c|c|c|c|c|c|c|c|}
\hline & \multicolumn{2}{|l|}{ Desire } & \multicolumn{2}{|c|}{ Arousal } & \multicolumn{2}{|c|}{ Lubrication } & \multicolumn{2}{|l|}{ Orgasm } & \multicolumn{2}{|c|}{ Satisfaction } & \multicolumn{2}{|l|}{ Pain } \\
\hline & $r$ & $p$ & $r$ & $p$ & $r$ & $p$ & $r$ & $p$ & $R$ & $p$ & $r$ & $p$ \\
\hline Age & $.355^{*}$ & 0.01 & -.023 & 0.721 & $-.187^{*}$ & 0.01 & $-.197^{*}$ & 0.01 & -.0 .084 & 0.05 & $-.267^{*}$ & 0.01 \\
\hline Edss & $.225^{*}$ & 0.01 & -.067 & 0.291 & $-.275^{*}$ & 0.01 & $-.249^{*}$ & 0.01 & 0.098 & 0.124 & $-0.183^{*}$ & 0.004 \\
\hline Depression & .006 & 0.05 & -.035 & 0.05 & -.048 & 0.05 & -.038 & 0.05 & .018 & 0.05 & -.044 & 0.05 \\
\hline Anxiety & .022 & 0.05 & -.026 & 0.05 & -.042 & 0.05 & -.036 & 0.05 & -.007 & 0.05 & -.061 & 0.05 \\
\hline Stress & -.060 & 0.05 & -.086 & 0.05 & -.090 & 0.05 & -.087 & 0.05 & -.028 & 0.05 & -.070 & 0.05 \\
\hline
\end{tabular}

EDSS $=$ Expanded Disability Status Scale; MS = multiple sclerosis.

*Correlation is significant at the 0.01 level (2-tailed).

Regarding our third hypothesis, age was found to be associated with most of the subscales of FSFI. According to FSFI, as the total score increases, the sexual function improves. In our case, the age increase correlates with lower FSFI scores (FSD existence). This is also in agreement with past studies ${ }^{2-15}$ showing that in Greek women with MS, age may be a sufficient reason for the prevalence of FSD.

As for menopause, $\mathrm{H} 4$ was that sexual dysfunction will be higher in women during menopause. From our analysis, it seems that high rates of sexual dysfunction were found also in women not in menopause. From these, it seems that menopause may be a risk factor for sexual dysfunction in women with MS but it is not the main factor because women of younger ages also seem to have high rates of sexual dysfunction.

Regarding the impact of severity of MS in sexual function of the patients, Szasz et $\mathrm{al}^{46}$ and Hulter et $\mathrm{al}^{45}$ found that patients with higher levels of disability experienced greater problems with their functioning. This finding was in contrast to the findings of Valleroy et al, ${ }^{14}$ Stenager et al, ${ }^{48}$ Mattson et al, ${ }^{49}$ McCabe et al, ${ }^{50}$ and Beier et al, ${ }^{51}$ that there is no correlation between the level of disability and sexual dysfunction. Thus, the impact of the level of disability on sexual dysfunction, therefore, remains unclear. In our study, as for this issue (H5), we found that disease severity measured by EDSS had also a negative correlation with most of the FSFI subscales apart from Desire and Satisfaction (disease severity was higher in patients with lower FSFI scores), which means that MS severity may have a positive impact on the prevalence of FSD.

In agreement with some studies and in contrast with others, we found no correlation between FSD and duration of MS. ${ }^{6,33,41,42}$ This was an unexpected finding that we found surprising and that needs more investigation. We suppose it has to do with the form of the disease (relapsing remitting vs progressive forms of the disease). ${ }^{42}$ Unfortunately, our patients usually do not know the form of the disease they have and we did not have access to their neurologic data.

From the overall discussion of our findings, it seems that our study enhances the knowledge we have about the prevalence of FSD in patients with MS in Greece because until now we had no data on these issues in this particular population. Of course, this was only a first attempt and needs many things to be done to have a deep understanding of FSD in MS.

Our study has some limitations such as the lack of a control group with similar demographic characteristics without MS. Future research, using a population of women in the same age range but without MS, and an age-matched group of women with another chronic disease, would be ideal. Another limitation is the lack of more detailed neurologic data, such as the MS type or the time from the last relapse. We tried to face this limitation through the use of EDSS, which can reflect the clinical impact of the disease on the patient. Another limitation is that our sample is not gathered from all over Greece, but is the data from the outpatient clinics of 2 hospitals. Also, both units are considered specific for neurologic diseases so the patients that are under follow-up are referred to us from almost all of Greece.

\section{CONCLUSION}

Although there are limitations to our study, we have been able to specifically show that FSD is common among MS patients, it is influenced by the age of the patients and the severity of the disease, and it is independent of the existence of depression, anxiety, and stress. Sexual dysfunction is well known as a reason for deteriorating QoL in women. For that, clinicians working with MS should proactively ask their female patients about their sexual life, especially when they are depressed, postmenopausal, or older.

Corresponding Author: Charalampos Konstantinidis, MD, FEBU, FECSM, Chasias Av. \& Spirou Theologou 1, Athens 13122, Greece. Tel: 210 2381003; Fax: 210 2381003; E-mail: konstantinidischaralampos@yahoo.com

Conflicts of Interest: The authors report no conflicts of interest.

Funding: None.

\section{STATEMENT OF AUTHORSHIP}

\section{Category 1}

(a) Conception and Design

Charalampos Konstantinidis; Konstantinos Skriapas 
(b) Acquisition of Data Charalampos Konstantinidis

(c) Analysis and Interpretation of Data Charalampos Konstantinidis; Moira Tzitzika; Bantis Athanasios; Archontia Nikolia; Michalis Samarinas; Zisis Kratiras; Charalampos Thomas

\section{Category 2}

(a) Drafting the Article Moira Tzitzika; Archontia Nikolia; Michalis Samarinas; Charalampos Thomas

(b) Revising It for Intellectual Content Charalampos Konstantinidis; Bantis Athanasios; Zisis Kratiras; Konstantinos Skriapas

\section{Category 3}

(a) Final Approval of the Completed Article Charalampos Konstantinidis; Moira Tzitzika; Bantis Athanasios; Archontia Nikolia; Michalis Samarinas; Zisis Kratiras; Charalampos Thomas; Konstantinos Skriapas

\section{REFERENCES}

1. Murray TJ. Multiple sclerosis: The history of a disease. New York, NY: Demos Publishing; 2005.

2. Schmidt EZ, Hofmann P, Niederwieser G, et al. Sexuality in multiple sclerosis. J Neural Transm (Vienna) 2005 Sep; 112(9):1201-1211.

3. Bronner G, Elran E, Golomb J, et al. Female sexuality in multiple sclerosis: The multidimensional nature of the problem and the intervention. Acta Neurol Scand 2010;121:289-301.

4. Ashtari F, Rezvani R, Afshar H. Sexual dysfunction in women with multiple sclerosis: Dimensions and contributory factors. J Res Med Sci 2014;19:228-233.

5. Foley FW. Introduction to intimacy and sexuality in MS. MS in Focus 2005;6:4.

6. Demirkiran M, Sarica $Y$, Uguz $S$, et al. Multiple sclerosis patients with and without sexual dysfunction: Are there any differences? Mult Scler 2006;12:209-214.

7. Schairer LC, Foley FW, Zemon V, et al. The impact of sexual dysfunction on health-related quality of life in people with multiple sclerosis. Mult Scler 2014;20:610-616.

8. Koch T, Kralik D, Eastwood S. Constructions of sexuality for women living with multiple sclerosis. J Adv Nurs 2002; 39:137-145.

9. McCabe MP, McKern S, McDonald E, et al. Changes over time in sexual and relationship functioning of people with multiple sclerosis. J Sex Marital Ther 2003;29:305-321.

10. McCabe MP. Relationship functioning and sexuality among people with multiple sclerosis. J Sex Res 2002;39:302309.

11. Celik DB, Poyraz EC, Bingöl A, et al. Sexual dysfunction in multiple sclerosis: Gender differences. J Neurol Sci 2013; 324:17-20.

12. Fraser C, Mahoney J, McGurl J. Correlates of sexual dysfunction in men and women with multiple sclerosis. J Neurosci Nurs 2008;40:312-317.
13. Zivadinov R, Zorzon M, Bosco A, et al. Sexual dysfunction in multiple sclerosis: II. Correlation analysis. Mult Scler 1999; 5:428-431.

14. Valleroy ML, Kraft $\mathrm{GH}$. Sexual disturbances arising from multiple sclerosis. Acta Neurol Scand 1984;70:299-306.

15. Nortvedt MW, Riise T, Frugard J, et al. Prevalence of bladder, bowel and sexual problems among multiple sclerosis patients two to five years after diagnosis. Mult Scler 2007;13:106-112.

16. Varanda S, Ribeiro da Silva J, Costa AS, et al. Sexual dysfunction in women with Parkinson's disease. Movement Disord 2016;31:1685-1693.

17. Yilmaz H, Polat HAD, Yilmaz SD, et al. Evaluation of sexual dysfunction in women with rheumatoid arthritis: A controlled study. J Sex Med 2012;9:2664-2670.

18. Fruehwald S, Loeffler-Stastka H, Eher R, et al. Depression and quality of life in multiple sclerosis. Acta Neurol Scand 2001; 104:257-261.

19. Zephir H, De Seze J, Stojkovic T, et al. Multiple sclerosis and depression: Influence of interferon beta therapy. Mult Scler 2003;9:284-288.

20. Avasarala JR, Cross AH, Trinkaus K. Comparative assessment of Yale Single Question and Beck Depression Inventory Scale in screening for depression in multiple sclerosis. Mult Scler 2003;9:307-310.

21. Patten SB, Beck CA, Williams JV, et al. Major depression in multiple sclerosis: A population-based perspective. Neurology 2003;61:1524-1527.

22. Solari A, Motta A, Mendozzi $L$, et al. Italian version of the Chicago multiscale depression inventory: Translation, adaptation and testing in people with multiple sclerosis. Neurol Sci 2004:24:375-383.

23. Janardhan V, Bakshi R. Quality of life in patients with multiple sclerosis: The impact of fatigue and depression. J Neurol Sci 2002;205:51-58.

24. Buvat J, Lemaire A. Sexuality of the diabetic woman. Diabetes Metab 2001;27:S67-S75.

25. Monga TN, Tan G, Ostermann HJ, et al. Sexuality and sexual adjustment of patients with chronic pain. Disabil Rehabil 1998;20:317-329.

26. Graziottin A. The biological basis of female sexuality. Int Clin Psychopharmacol 1998;13(Suppl. 6):S15-S22.

27. Channon LD, Ballinger SE. Some aspects of sexuality and vaginal symptoms during menopause and their relation to anxiety and depression. Br J Med Psychol 1986;59(Pt 2):173-180.

28. Nappi RE. Sexuality and menopause. In: Erkkola R, ed. The menopause. Philadelphia: Elsevier; 2006. p. 143-154.

29. Dennerstein $L$, Alexander $J L$, Kotz K. The menopause and sexual functioning: A review of the population-based studies. Annual Review of Sex Research 2003;14:64-82.

30. Palacios S, Tobar AC, Menendez C. Sexuality in the climacteric years. Maturitas 2002;3(Suppl. 1):S69-S77. 
31. Bove R, Healy BC, Secor E, et al. Patients report worse MS symptoms after menopause: Findings from an online cohort. Mult Scler Relat Dis 2015;4:18-24.

32. Tzortzis V, Skriapas K, Hadjigeorgiou G, et al. Sexual dysfunction in newly diagnosed multiple sclerosis women. Mult Scler 2008;14:561-563.

33. Lovibond SH, Lovibond PF. Manual for the Depression Anxiety Stress Scales. 2nd edition. Sydney: Psychology Foundation; 1995.

34. Lovibond PF, Lovibond SH. The structure of negative emotional states: Comparison of the Depression Anxiety Stress Scales (DASS) with the Beck Depression and Anxiety Inventories. Behav Res Ther 1995;33:335-343.

35. Lyrakos NG, Arvaniti C, Smyrnioti M, et al. Translation and validation study of the Depression Anxiety Stress Scale in the Greek general population and in a psychiatric patient's sample. Eur Psychiatry 2011;26(Suppl. 1):1731.

36. Zachariou A, Filiponi M, Kirana PS. Translation and validation of the Greek version of the female sexual function index questionnaire. Int J Impot Res 2017;29:171-174.

37. Rosen R, Brown C, Heiman J, et al. The Female Sexual Function Index (FSFI): A multidimensional self-report instrument for the assessment of female sexual function. J Sex Marital Ther 2000;26:191-208.

38. Hatzichristou D, Kirana P, Banner L, et al. Diagnostic evaluation of sexual dysfunctions in men and women and the use of symptom scales and questionnaires. J Sex Med 2016;13:11661182.

39. Kurtzke JF. Rating neurologic impairment in multiple sclerosis: an expanded disability status scale (EDSS). Neurology 1983; 33:1444-1452.

40. Ghajarzadeh $M$, Jalilian R, Mohammadifar $M$, et al. Sexual function in women with multiple sclerosis. Acta Med Iran 2014:52:315-318.

41. Gumus $\mathrm{H}$, Akpinar Z, Yilmaz H. Effects of multiple sclerosis on female sexuality: A controlled study. J Sex Med 2014;11:481486.
42. Kremechutzky M, Rice GP, Baskerville J, et al. The natural history of multiple sclerosis: A geographically based study 9: Observations on the progressive phase of the disease. Brain 2006;129(Pt 3):584-594.

43. Zorzon M, Zivadinov R, Bosco A, et al. Sexual dysfunction in multiple sclerosis: A case control study. I. Frequency and comparison of groups. Mult Scler 1999;5:418-427.

44. Zorzon M, Zivadinov R, Monti Bragadin L, et al. Sexual dysfunction in multiple sclerosis: A 2-year follow-up study. J Neurol Sci 2001;187:1-5.

45. Hulter BM, Lundberg PO. Sexual function in women with advanced multiple sclerosis. J Neurol Neurosurg Psych 1995; 59:83-86.

46. Szasz G, Paty D, Lawton-Speert S, et al. A sexual functioning scale in multiple sclerosis. Acta Neurol Scand Suppl 1984; 101:37-43.

47. Aisen ML, Sanders AS. Sexual dysfunction in neurologic disease: mechanisms of disease and counselling approaches. AUA Update Series Lesson 35, Volume XVII, 1998.

48. Stenager $E$, Stenager $E$, Jensen $K$, et al. Multiple sclerosis: Sexual dysfunctions. J Sex Educ Ther 1990;16:262269.

49. Mattson D, Petrie M, Srivastava DK, et al. Multiple sclerosis. Sexual dysfunction and its response to medications. Arch Neurol 1995;52:862-868.

50. McCabe M, McDonald E, Deeks A, et al. The impact of multiple sclerosis on sexuality and relationships. J Sex Res 1996; $33: 241$.

51. Beier K, Goecker D, Babinsky S, et al. Sexualität und partnerschaft bei multipler sklerose-Ergebnisse einer empirischen studie bei betroSffenen und ihren partnern. Sexuologie 2002; 9:4-22.

\section{SUPPLEMENTARY DATA}

Supplementary data related to this article can be found at https://doi.org/10.1016/j.esxm.2018.11.003. 